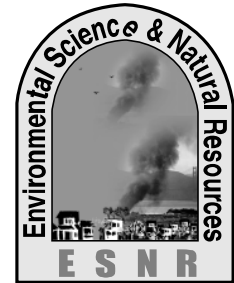

\title{
Effect of Growth Promoter (Rapid Growth) as a Supplementation on The Growth Performance Feed Utilization of Monosex Tilapia
}

\author{
A.F.M M. Islam, M.T. Zaman and M.M. Rahman
}

Department of Aquaculture, Bangladesh Agricultural University, Mymensingh

\begin{abstract}
The present study was conducted in farmer's ponds at field level of Muktagachha upazilla to find out the effect of growth promoter on growth performance and feed utilization of monosex Tilapia fish. Growth promoter was used in the experimental cultured farm. This growth enhancing aqua drugs was used in feeds of Tilapia. The results indicated that the growth promoter was the best treatment which significantly $(\mathrm{P} \leq 0.05)$ increased of all growth performances (final weight, AWG, ADG and SGR), improved FCR, and best economic efficiency. It was clearly observed that there were distinct impacts of growth promoter on fish growth and production. In the present study water quality parameters were within the suitable range. Production of Tilapia i.e. 4650 $\mathrm{kg} / \mathrm{acre}$ in promoter treated ponds whereas $3666 \mathrm{~kg} / \mathrm{acre}$ in non treated ponds were recorded. Food conversion ratio (FCR) was 1.70 and 1.38 were found in the controlled and treated pond respectively. Clinically the treated fishes did not show any remarkable changes. There were no adverse effects on water quality criteria among all experimental treatments. It could be concluded that the inclusion of the commercial probiotic Rapid Grow at a level of $0.05 \mathrm{mg} \mathrm{Kg}^{-1}$ diet at stocking density rate of $250 \mathrm{fish} / \mathrm{decimal}$ of mono-sex Tilapia $O$. niloticus is useful to get the best fish performance with friendly effects on the environment.
\end{abstract}

Keywords: Growth Promoter, Supplementation, Growth Performance, Feed Utilization, Survival Rate, Specific Growth Rate.

\section{Introduction}

Tilapia is one of the most important groups of fish for aquaculture with annual production exceeds 500,000 metric tons in Bangladesh (FAO, 2011). However, their aquaculture production has been developed remarkably during the last few decades due to the increased level of intensification and cultured area.The global aquaculture industry currently accounts for over $45 \%$ of all seafood consumed. This figure has been projected to increase $75 \%$ over the next 20 years (FTU, 2007). Some of the most utilized growth-promoting feed additives include hormones, antibiotics, ionospheres and some salts (Klaenhammer and Kullen, 1999).

Probiotics are also used as feed additives which are defined as live microbes that may serve as dietary supplements to improve the host intestinal microbial balance and growth performance (Gatesoupe, 1999). The probiotic in aquaculture have been shown to have several modes of action: competitive exclusion of pathogenic bacteria through the production of inhibitory compounds; improvement of water quality; enhancement of immune response of host species and enhancement of nutrition of host species through the production of supplemental digestive enzymes (Carnevali et al., 2006). Thus, the use of probiotic in aquaculture has received some attention (Abdel Amid et al., 2009). Rapid Grow can enhance the metabolism and energy of fish body cells, raise the efficiency of feed utilization and balance the secretion of various secretary glands. Most studies concerned with the effects of probiotics on cultured aquatic animals have emphasized a reduction in mortality or, conversely, increased survival, improved resistance against disease.Thus, the present study was conducted to determine the effect of using graded levels of probiotic (Rapid Grow) on growth performance, feed utilization, and economic evaluation of feed costs of Monosex tilapia (O.niloticus).

The specific objectives of the study is to authenticate the product (Growth Promoter) towards the farmer,To compare fish production between culture systems using chemicals and without chemical,To study the impact of use of chemicals on feed utilization and productivity on Tilapia

\section{Materials and Methods}

The present study was conducted in Bot-tala Bazar, Dapunia, Muktagachha, and Mymensingh which are owned by a farmer. The experimental fish were stocked in two experimental ponds supplied with fresh water. The experiment was carried out for a period of six months from July to December, 2011 to evaluate the effect of dietary probiotic Rapid Grow supplementation as a growth promoter on growth performance and feed utilization of monosex Tilapia in pond culture system.

\section{Experimental design}

Table 1. Experimental layout of monosex male tilapia culture

\begin{tabular}{|l|c|c|c|}
\hline \multicolumn{1}{|c|}{ Pond } & $\begin{array}{c}\text { Pond } \\
\text { Size }(\mathrm{dec})\end{array}$ & $\begin{array}{c}\text { Stocking } \\
\text { density/dec. }\end{array}$ & $\begin{array}{c}\text { Total } \\
\text { Stocking } \\
\text { Size }(\mathrm{g})\end{array}$ \\
\hline Treatment pond & 50 & 250 & 12500 \\
\hline Control pond & 50 & 250 & 12500 \\
\hline
\end{tabular}


After 7 days of liming, underground water was entered into the ponds by pumping. The ponds were newly excavated for tilapia culture and the banks were planted with grass to prevent soil erosion. After one week, lime was applied at the rate of $1 \mathrm{~kg} /$ decimal. Monosex

\section{Selection of feed}

The study was conducted by the artificial fish feed which were suitable for Tilapia (0. niloticus) culture. Especially pellet feeds were used which was male tilapia (0. niloticus) fry were collected from the 'Reliance Hatchery' and transported to the farm by plastic made drum having oxygenation facility and then transferred to grow out ponds after acclimatization.

sinking or semi-sinking. The name of feed was "Biswas feed" from a well developed fish feed company.

\section{Feeding strategy}

Table 2. Feeding strategy for different types of feeds

\begin{tabular}{|c|c|c|c|}
\hline Culture period & $\begin{array}{c}\text { Types of supplied } \\
\text { feed }\end{array}$ & $\begin{array}{c}\text { Feeding } \\
\text { frequency }\end{array}$ & $\begin{array}{c}\text { Feed rate } \\
\text { of body weight) }\end{array}$ \\
\hline $1-15$ days & Nursery & 3 times & $15 \%$ \\
\hline $16-30$ days & Starter & 3 times & $10 \%$ \\
\hline $31-45$ days & Starter & 3 times & $7 \%$ \\
\hline $46-60$ days & Grower & 3 times & $5 \%$ \\
\hline $61-90$ days & Grower & 3 times & $4 \%$ \\
\hline
\end{tabular}

\section{Water quality parameters}

In the present study, water sample were collected from two ponds. Recording on the spot data and collection of samples were made between 9.00 A.M. to 11.30 A.M. Water temperatures, Dissolved Oxygen (D.O), $\mathrm{pH}$, transparency and total alkalinity were recorded fortnightly.

\section{Selected group of growth promoter}

Growth promoter (Rapid Grow) was selected through personal contract with the area manager and representative of Fish Tech Pharmaceuticals Company.

\section{Estimation of experimental data on growth}

Experimental data collected during the growth trial were used to determine the Weight gain,

Average daily weight gain,Specific growth rate (SGR) (\% per day) and Food conversion ratio (FCR) growth parameters.

\section{Estimation of survival rate (\%)}

The survival rate of fish for each treatment was examined on the basis of number of fish harvested at end of the experiment. The survival rate was calculated by counting the actual number of fishes survived, divided by the initial number stocked and multiplying by 100 and thus.

$$
\text { Survival rate }(\%)=\frac{\text { No of fishes survived } \times 100}{\text { No of fishes stock }}
$$

\section{Statistical analysis}

The data obtained during the experiment were statistically analyzed to see whether the influence of different stocking densities on the growth, survival and production of fish were significant or not. One way analysis of variance (ANOVA) was performed to test the significance of variation among the treatments. Significant differences among different treatment means were identified by SPSS (Statistical Package for Social Science).

\section{Economic analysis}

A simple economic analysis was done to estimate the net profit from different treatments. The cost of leasing ponds was not included in the total cost. An additional $7.5 \%$ on total cost was included as operational cost according to ADCP (1983).

\section{Results}

For the study of growth performances of mono-sex tilapia under supplementation of Growth Promoter (Rapid Grow) the water quality parameters were monitored throughout the experimental period of both control and treatment ponds.

Water quality parameters

Water temperature

Dissolved oxygen 

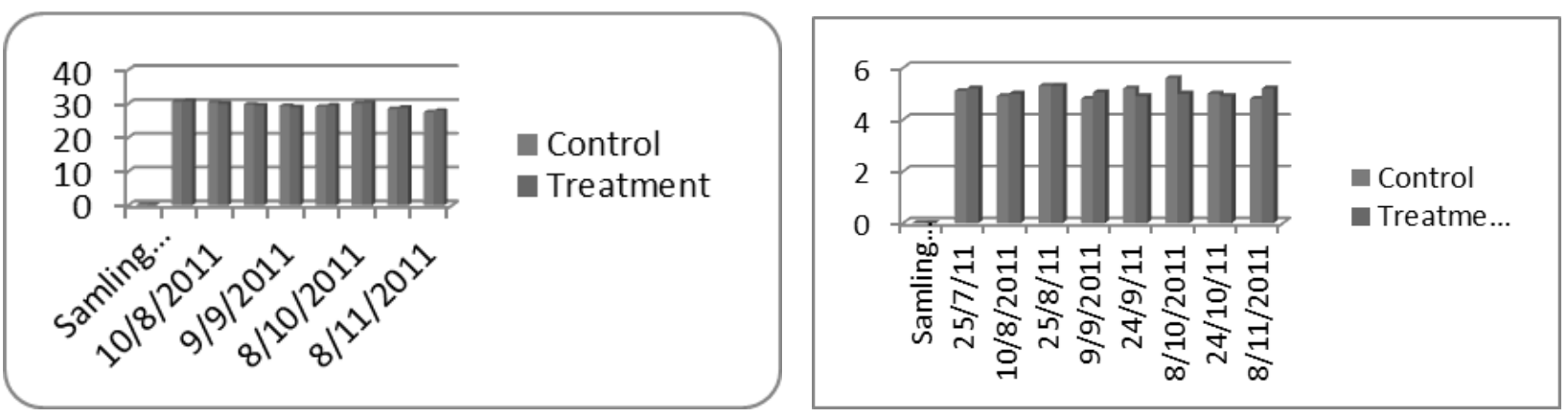

Fig 1. Fortnightly fluctuations of dissolved oxygen $(\mathrm{mg} / \mathrm{l})$ of the ponds under treatments during the experimental period

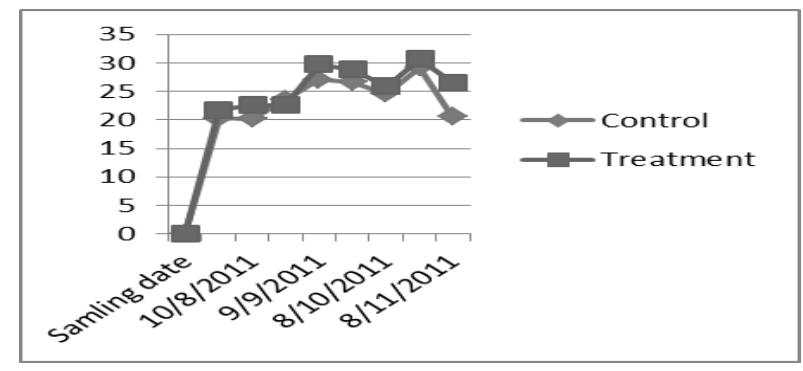

Fig 2. Fortnightly fluctuations of $\mathrm{pH}$ of the ponds under treatment and control during the experimental period

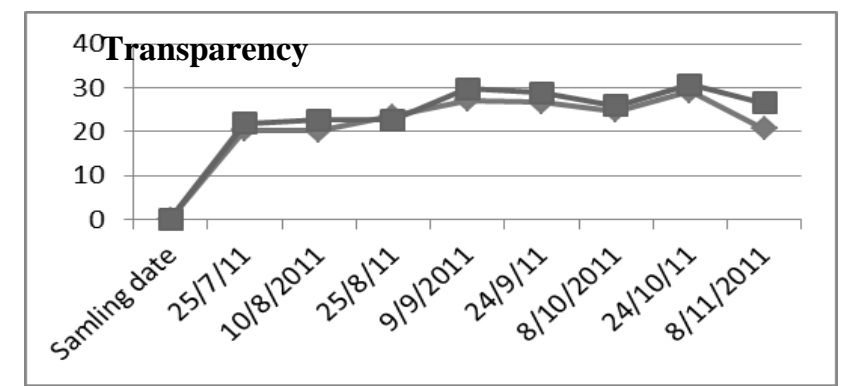

Fig 3. Fortnightly fluctuations of transparency $(\mathrm{cm})$ of the ponds under treatment and control during the experimental period

\section{Total Alkalinity}

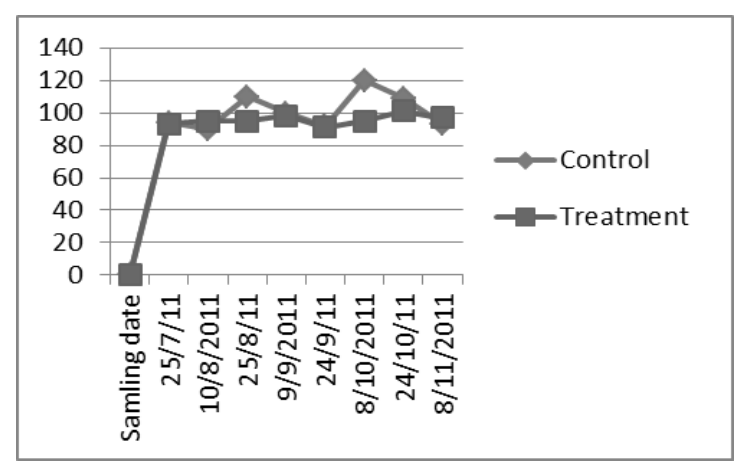

Fig 4. Fortnightly fluctuations of total alkalinity $(\mathrm{mg} / \mathrm{l})$ of the ponds under treatment and control during the experimental period

\section{Weight gain $(\mathrm{g})$}

In the study period the mean final weights of fish were the significantly highest mean net weight gain (193.55) was found in treated and the lower mean net weight gain
(162.67) was found in controlled pond .Variations of weight gain (g) at 15 days interval among the control and treatments have been shown in Fig 5.

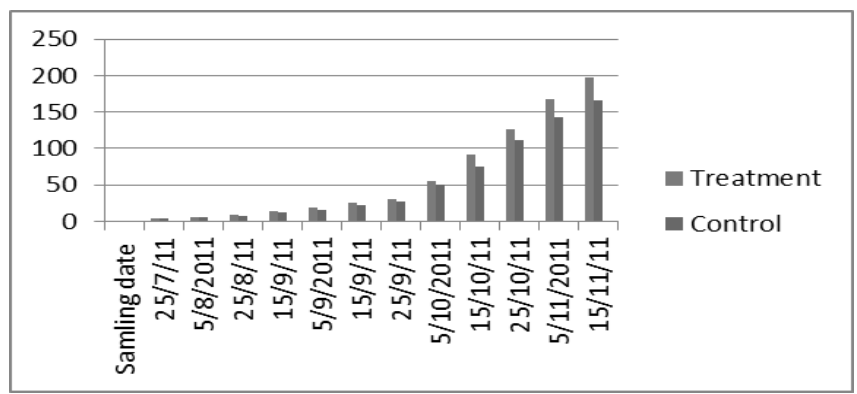

Fig 5. Fortnightly fluctuations of weight gain $(\mathrm{g})$ of fish under treatment and control during the experimental period 


\section{Average daily weight gain (g)}

Significantly $(\mathrm{P} \leq 0.05)$ the highest average daily weight gain (1.65) was found in treatment and the lowest average daily weight gain (1.35) was obtained in controlled fishes. Variation of growth in terms of average daily weight gain (g) among the control and treatments has been shown in Fig 6..

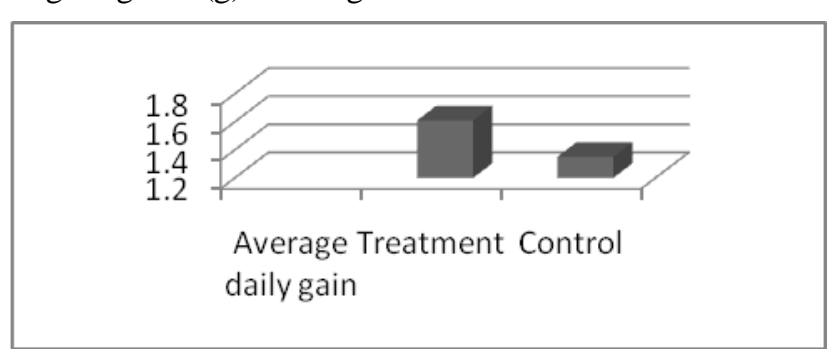

Fig. 6. Variation of growth in terms of average daily weight gain $(\mathrm{g})$ among the control and treatments

\section{Food conversion ratio (FCR)}

Food conversion ratio (FCR) was 1.70 and 1.38 in the control and treatment in case of Tilapia. However, in case of Tilapia, FCR in the treated Tilapia was significantly reduced that of control .

Table 3. Food conversion ratio (FCR) for Tilapia

\begin{tabular}{|l|c|c|}
\hline \multicolumn{1}{|c|}{$\begin{array}{c}\text { Treatments } \\
\text { FCR }\end{array}$} & \multicolumn{2}{c|}{ Parameters } \\
\cline { 2 - 3 } & Control & Treatment \\
\hline Feed $(\mathrm{g})$ & 3125000 & 3250000 \\
\hline Weight $(\mathrm{g})$ & 1833000 & 2345000 \\
\hline FCR & 1.70 & 1.38 \\
\hline Mean & \multicolumn{2}{|c|}{1.54} \\
\hline
\end{tabular}

\section{Weight gain (g)}

The mean weight gain of fish at the end of the experiment was significantly higher in treated pond $(193.55 \mathrm{~g})$ than in control $(162.6 \mathrm{~g})$ is shown in Table.

Table 4: Weight gain in Tilapia in two different experimental ponds

\begin{tabular}{|l|c|c|}
\hline \multicolumn{1}{|c|}{$\begin{array}{c}\text { Treatments } \\
\text { FCR }\end{array}$} & \multicolumn{2}{c|}{ Parameters } \\
\hline & Control & Treatment \\
\hline $\begin{array}{l}\text { Mean final } \\
\text { weight (g) }\end{array}$ & $166.67 \pm 3.94$ & $197.55 \pm 4.01$ \\
\hline $\begin{array}{l}\text { Mean initial } \\
\text { weight (g) }\end{array}$ & $4 \pm 1.56$ & $4 \pm 1.56$ \\
\hline Weight gain (g) & 162.67 & 193.55 \\
\hline Mean & \multicolumn{2}{|c|}{178.11} \\
\hline
\end{tabular}

\section{Specific growth rate (SGR)}

The initial weight and culture period was same in both control and treatment. The variation has been shown in final weight rather than in control. The higher specific growth rate of tilapia in treatment is 0.014 and in control 0.013.The mean SGR in both treatment and control is 0.0135 .

Table 5. Specific growth rate (SGR) of Tilapia in two different experimental ponds.

\begin{tabular}{|l|c|c|}
\hline \multirow{2}{*}{$\begin{array}{c}\text { Treatments } \\
\text { Specific growth rate } \\
\text { (SGR) }\end{array}$} & Control & Treatment \\
\cline { 2 - 3 } & & 2.221 \\
\hline $\log \mathrm{W}_{2}$ & 0.60 & 0.60 \\
\hline $\log \mathrm{W}_{1}$ & 120 & 120 \\
\hline $\mathrm{T}_{2} \mathrm{~T}_{1}$ & 0.013 & 0.014 \\
\hline SGR (\% day) & \multicolumn{2}{|c|}{0.0135} \\
\hline Mean (\% day) & \multicolumn{2}{|c|}{} \\
\hline
\end{tabular}

\section{Economic analysis}

A simple economic analysis was done to estimate the net profit from different treatment and control. The cost of production was based on the present whole sale market price 2011 in consideration of the inputs used. The feed cost was TK.25/kg. The selling price of tilapia was $75 \mathrm{Tk} / \mathrm{kg}$ under treatment and control. The cost of leasing pond was not included in the total cost. An additional 7.5 on total cost was included as operational cost according to ADCP (1983). From the Table 12, It was found that the gross profit was highest (71095 Tk) in treatment compared to control (37850 $\mathrm{Tk}$ ). The significantly ( $\mathrm{P} \leq 0.05$ ) highest net profit (71095 Tk) was obtained with treatment.

Table 6.

\begin{tabular}{|l|c|c|}
\hline Parameters & Control & Treatment \\
\hline Input cost / 50Decimal (in Taka) & 12500 & 12500 \\
\hline Fingerlings cost & 78125 & 81280 \\
\hline Feed cost & 9000 & 9000 \\
\hline Pond preparation and maintenance cost & Nil & 2000 \\
\hline Growth Promoter cost & 99625 & 104780 \\
\hline Gross cost & Return /hectare (in Taka) \\
\hline \multicolumn{2}{|c|}{137475} & 175875 \\
\hline Gross income from sale (Tk. 75/kg) & 37850 & 71095 \\
\hline Profit (in Taka) & & \\
\hline
\end{tabular}




\section{Discussion}

As tilapia culture continues to expand worldwide, there is a growing pressure to minimize production cost associated with diet supplementation. Optimization of diets and feeding strategies are two mechanisms that could be utilized to help reach these goals. To facilitate the reduction in nutrient loading within culture systems, the concept of low-pollution diets has been adopted as a means to minimize waste output while maximizing the mass of fish produced. In this regard, Eid et al. (2008) demonstrated that the effect of two different commercial feed additives on growth performance of monosex Nile tilapia fingerlings. These results revealed that using Biogen ${ }^{\circledR}$ at level of $0.1 \%$ was the best in terms of growth performance and economic evaluation.

During the present study the growth performances of mono-sex male Tilapia (Oreochromis niloticus) varied in treatment and control due to use of growth promoter. The highest net weight gain $(193.55 \mathrm{~g})$ was found in treatment with using Growth Promoter Rapid Grow. This phenomenon indicated that there was a lower community feelings among the fishes which influenced them to take food properly and it might be absent in the treatments with using of growth promoter. The lowest growth (162.67) was obtained in control with not using of growth promoter. At the end of the experimental period (120 days), the group of fish fed the growth promoter grew as well or better than the group of fish fed the control diet (control). Whereas, the final body weight of the fish groups fed on Rapid Grow had significantly $(\mathrm{P}<0.05)$ higher final body weight than the control groups. However, the lowest final body weight (162.67) was achieved by the group of fish fed the control diet. Analysis of variance for weight gain followed the same trend as in final body weights. On the other hand, the fish groups fed on growth promoter had significantly $(\mathrm{P}<0.05)$ higher SGR than the rest of experimental groups. However at the end of the experiment, SGR values were 2.221 (control diet), and 2.29 for fish groups fed on growth promoter Rapid Grow. These results are in agreement with the results of Mehrim (2001), and Diab, et al. (2002) for tilapia. Khattab et al. (2004) and Mohamed et al. (2007) reported that the Nile tilapia (O. niloticus) fingerlings fed on diets supplemented by probiotics exhibited greater growth than those fed with the control diet. Also, they reported that the diet contained $30 \%$ protein supplemented with Biogen ${ }^{\circledR}$ at level of $0.1 \%$ produced the best growth performance and feed efficiency, moreover they also reported that Biogen ${ }^{\circledR}$ is an appropriate growth-stimulating additive in tilapia cultivation. Similar results were reported using bacteria as a probiotics by Kozasa (1986) for yellowtail (Seriola lalandei), Similar trend was found, in this respect with Noh et al. (1994) and Bogut et al. (1998) who studied the effect of supplementing common carp feeds with different additives, including antibiotics, yeast $(S$. cerevisiae) and bacteria (S. faecium). They observed better growth with probiotic-supplemented diets but obtained the best growth with the bacterium. It is also necessary, to consider the possibility of interspecies differences with the use of the probiotics. In contrary with these findings Abdel Hamid et al. (2002) who found that growth promoter supplementation did not significantly improve growth performance in tilapia fish.

\section{Conclusion}

The study was conducted for a period of six months from July to December 2011 in farmer's pond at field level and 2 experimental ponds each of 50 decimal to find out the effect of growth promoter Rapid Grow as a supplementation on the growth performance and feed utilization of monosex Tilapia. The amount of feed was calculated according to the weight of fish in each treatment. Random sampling was done to measure the weight of fish, to adjust the feeding rate and to monitor the water quality parameters. The proximate composition of experimental feed was determined according to standard procedure given in AOAC (1980). Growth parameters were calculated after completion of the experiment and one way analysis of variance (ANOVA) was used for statistical analysis of data and was followed by Duncan's New Multiple Range Test (DMRT) to identify the significant variation among the treatments at 5\% level of significance. The profit obtained through such type of fish culture was calculated by a simple economic analysis. The water quality parameter such as temperature, dissolved oxygen, $\mathrm{pH}$, were monitored at 10 days interval. The ranges of water quality parameters were, temperature 27.10 to $32.30^{\circ} \mathrm{C}$, dissolved oxygen 4.8 to $5.6, \mathrm{pH} 7.7$ to 8.8 and all the values are within limit of good aquaculture water quality. No significant variations of water quality were observed among different treatments. The result of growth response of fish fed on Growth promoter showing highest total growth then the fish fed with normal diet. On the contrary least FCR values were found in treatment. The highest percentage of FCR values was recorded in control then in treatment .Effective feed utilization and increased growth performance were recorded on treatment. Thus the finding of the present experiment indicate that the use of growth promoter directly affect the growth performance and feed utilization of monosex Tilapia. In last, all results obtained indicated that growth promoter Rapid Grow at $50 \mathrm{mg} / 100 \mathrm{~kg}$ feed produced a positive effect on growth and feed utilization of tilapia. In addition, the immune responses were substantial in both treatment groups following the challenge with bacterial infection. Further work is suggested on clinical and histopathological aspects in different organs whether there is any adverse effect on the health of chemical treated pond. 


\section{References}

Abdel hamid, A.M., F.F.M. Khalil, M.I. El-Barbary. 2002. Feeding Nile tilapia Biogen to detoxify aflatoxin diets. In Proceeding of the 1st Annual Scientific

AOAC, 2000. Association of Official Analytical Chemists, Official methods of analysis, 17th Ed. Washington, DC.,USA.

Bogut, I., Z., 'Z`., Milakovic, S.R. Zimmer. 1998. Influence of probiotic ( $S$. faecium ) on growth and content of intestinal microflora in carp (Cyprinus carpio). Czech. J. Anim. Sci., 43:231-235.

Carnevali and A. Cresci. 2006. Growth improvement by probiotic European sea bass juveniles (Dicentrarchus labrax, L.), with particular attention to IGF-1, myostatin and cortisol gene expression. Aquaculture, 258: 430-438.

Diab, A.S., O.G. EL-Nagar, and M.Y. Abd-El-Hady. 2002. E valuation of Nigella sativa L. (black seeds; baraka), Allium sativum (garlic) \& Biogen as a feed additives on growth performance of Oreochromis niloticus fingerlings. Vet. ed. J., Suez Canal University, V2 745-753.

Eid, A. and K.A. Mohamed. 2008. Effect of using probiotic as growth promoter in commercial diets for monosex Nile tilapia (Oreochromis niloticus) fingerlings. $8^{\text {th }}$ International Symposium on Tilapia in Aquaculture, Cairo, Egypt, 12-14 Oct., pp: 241-253.

FAO, 2011. Twenty year fishery development plan for Bangladesh, USA. 23pp.

FTU 2007. Feed Technology Update. Insects offer a promising solution to the protein bottle neck. Volume 2, Issue 6.
Gatesoupe, F.J. 1999. The use of probiotics in aquaculture. Aquaculture, 180: 147- 165.

Khattab, Y.A.E, Shalaby, A.M.E., Sharaf Saffa, M., El-Marakby, H. and E. H.

RizlAlla. 2004. The physiological changes and growth performance of the Nile Tilapia (Oreochromis niloticus) after feeding with Biogen ${ }^{\circledR}$ as growth promoter. Egypt. J. Aquat. Biol. Fish., 8(2): 145-158.

Klaenhammer, T.D. and M.J. Kullen. 1999. Selection and design of probiotics. Int. J. Food Microbiology., 50: 45- 57.

Kozasa, M. 1986. Toyocerin Bacillus toyoi.as growth promotor for animal feeding. Microbiol. Aliment. Nutr. 4, 121-135.

Mehrim, A.I.M. 2001. Effect of some chemical pollutants on growth performance, feed and nutrient utilization of Nile Tilapia $(O$. niloticus). M.Sc. thesis, Saba. Basha. Alex. University, $215 \mathrm{pp}$.

Mohamed, K.A.,B. Abdel Fattah and A.M.S. Eid. 2007. Evaluation of using some feed additives on growth performance and feed utilization of monosex Nile tilapia (Oreochromis niloticus) fingerlings. Agricult. Res. Jour., Suez Canal University, 7: 49-54.

Noh, H., K.I., Han, T.H. Won, and Y.J. Choi. 1994. Effect of antibiotics, enzymes yeast culture and probiotics on the growth performance of Israeli carp. Korean J. Anim., Sci. 36: $480-486$ 